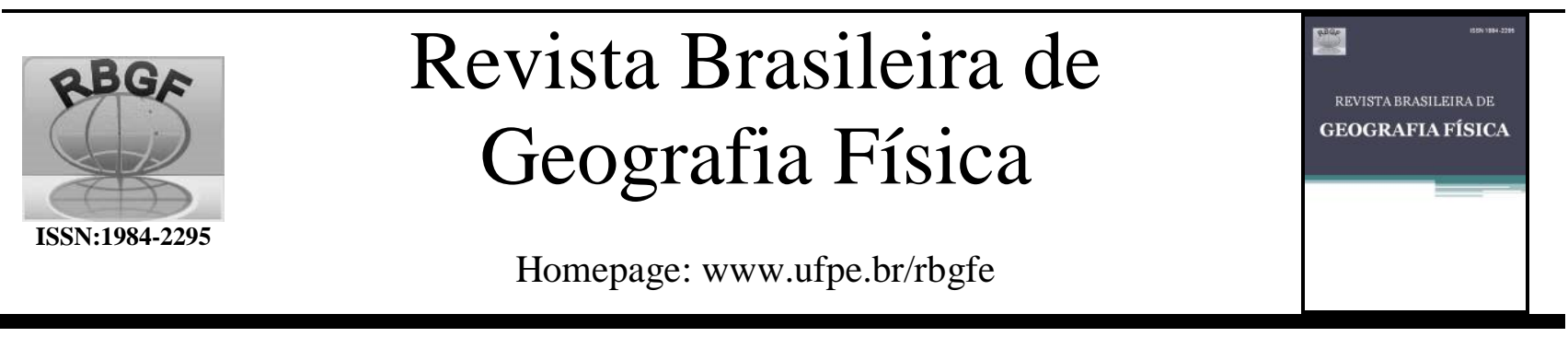

\title{
Mapeamento da desertificação da Região de Desenvolvimento Sertão do São Francisco com base na cobertura vegetal e nas classes de solos
}

\author{
Iêdo Bezerra Sá1, Tony Jarbas Ferreira Cunha' ${ }^{1}$, Tatiana Ayako Taura², Marcos Antônio Drumond ${ }^{1}$
}

\begin{abstract}
${ }^{1}$ Pesquisador da Embrapa Semiárido, Petrolina, Pernambuco, Brasil, \{iedo.sa; tony.cunha; marcos.drumond $\} @$ embrapa.br; ${ }^{2}$ Analista da Embrapa Semiárido, Petrolina, Pernambuco, Brasil, tatiana.taura@embrapa.br.
\end{abstract}

Artigo recebido em 10/09/2015 e aceito em 30/11/2015

\begin{abstract}
RESUMO
Na região Semiárida do Estado de Pernambuco existe grande diversidade na paisagem natural, onde a vegetação, os solos e o clima geram uma multiplicidade de situações que concorrem para formação de diferentes ecossistemas e habitats com grande potencial ecológico e ambiental. Nesta região, a vegetação é caracterizada por diferentes fisionomias, variando de áreas com formações arbustivas, com cobertura do solo muito escassa e quase ausente, a formações arbóreas com níveis de cobertura bastante densas. De modo análogo, nesta região ocorre uma grande variedade de solos, que por suas características, manejo e situação no relevo podem potencializar os processos erosivos, determinantes no desencadeamento da desertificação. Considerando as interrelações destas duas variáveis ambientais, este trabalho tem o objetivo de realizar um diagnóstico das áreas susceptíveis à desertificação da Região de Desenvolvimento Sertão do São Francisco - RDSF, tendo como base o cruzamento das informações da cobertura vegetal natural e das classes de solos. Para tanto, foram utilizados o recorte do mapeamento da cobertura vegetal e uso do solo e o recorte do mapeamento de solos da RDSF. Foram estabelecidos critérios para susceptibilidade da cobertura vegetal, assim como para as classes de solos presentes na área. Executou-se a intersecção destas duas bases de informação para o perfil da sensibilidade à desertificação. Os resultados mostram que a RDSF tem os seguintes valores das áreas em processos de desertificação: $1,77 \%$ na classe ausente ou fraca; $74,74 \%$ na classe moderada; $0,35 \%$ na classe acentuada e 23,14\% na classe severa. Deste modo, observa-se que aproximadamente $98 \%$ da RDSF encontram-se na situação de sensibilidade à desertificação em que predominam as classes de Moderada a Severa.
\end{abstract}

Palavras-chave: desertificação, São Francisco, semiárido, solos.

\section{Desertification mapping of "Sertão" San Francisco Development Region based on the vegetation and the soil classes}

\begin{abstract}
In the semiarid region of the state of Pernambuco there are plenty of biophysics where vegetation, climate, soils, and the various faces and the relationships and processes that take place among them generate the formation of different ecosystems and habitats with great potential ecological and environmental. There are a range of vegetation types, ranging from shrubby coverage areas up to very sparse and mostly absent vegetation areas, which demonstrated high desertification process occurring. Similarly, a variety of soils that is in the region along with vegetation makes this a region of great variation from the viewpoint of environmental supply. This article deals with the realization of a diagnosis of environmental sensitivity to desertification of São Francisco Development Region seeking spatialize the different situations in which the environment fulfills a greater or lesser extent, its role as provider of environmental services. For this, we used the cutting mapping of existing vegetation and soil mapping of the state and the established criteria, as well as edaphic vegetation cover, featuring the susceptibility to degradation and performed the intersection of these two bases of information to profile the sensitivity to desertification. The results show that São Francisco Development Region has the following values of areas undergoing desertification: $1.77 \%$ in weak class; $74.74 \%$ in the moderate class; $0.35 \%$ in sharp class, and $23.14 \%$ in severe class.
\end{abstract}

Keywords: desertification, São Francisco, Semi-arid region, soils.

Sá, I. B.; Cunha, T. J. F.; Taura, T. A.; Drumond, M. A. 


\section{Introdução}

O estado de Pernambuco possui cerca de $80 \%$ do seu território sob a ação de clima semiárido, com amplas repercussões ambientais, destacando-se: a escassez de água, solos rasos, baixa fertilidade agrícola evapotranspiração elevada e processos de desertificação. Associado a este contexto ambiental, tem-se uma histórica estrutura de relações sociais e de produção, ainda arcaica, com forte pressão sobre os recursos naturais, sobretudo água, solos e vegetação natural (Brasil, 2004).

A degradação ambiental que acompanhou essa organização sócio espacial vem se agravando progressivamente e produzindo, não só a perda dos recursos, com a transformação e supressão dos ecossistemas naturais, mas também desestruturando bases produtivas locais e regionais. Os reflexos sociais são muito negativos, sobretudo, pobreza, analfabetismo, desagregação das famílias, violência e êxodo. $\mathrm{O}$ estresse ambiental decorrente é potencializado, resultando em perda ecológica, falência das estruturas e das organizações sociais e migração.

Identificar e compreender esses processos, intrinsecamente associados à desertificação, bem como o aprimoramento do planejamento sócioeconômico-ambiental, é vital para a reversão de situações-limite, principalmente onde a desertificação está em pleno processo de expansão.

A Convenção das Nações Unidas para a Luta Contra a Desertificação atribui a origem da desertificação às interações complexas entre fatores físicos, biológicos, políticos, sociais, culturais e econômicos. Com relação às variações climáticas, quando a temperatura aumenta e permanece alta durante vários meses e as chuvas são raras e irregulares, a vegetação cresce com dificuldade. Trata-se do fenômeno chamada seca, termo que designa uma condição natural de algumas regiões, que se produz quando as chuvas são significativamente menores que os níveis normais registrados, e que acarretam graves desequilíbrios hidrológicos que prejudicam os sistemas de produção agrícola (Brasil, 2004).

Quanto às atividades humanas nas regiões onde a maior parte dos recursos econômicos depende da exploração agrícola, existe pouca ou nenhuma fonte alternativa de ingressos. Os solos se empobrecem devido à sua utilização excessiva e ao abandono ou diminuição do período de pousio ou descanso, necessário para manter a produtividade da terra. Isto leva à perda de fertilidade, que, por sua vez, limita o crescimento das plantas. Tudo isso ocasiona uma redução da cobertura vegetal, deixando os solos nus e mais vulneráveis aos processos erosivos.

Como se pode verificar, a desertificação é o resultado acumulado de um contexto climático severo e da utilização inapropriada das terras. Podem-se destacar quatro atividades humanas que constituem as suas causas mais diretas: o cultivo excessivo que desgasta os solos; o sobrepastejo e o desmatamento, que destroem a cobertura vegetal que protege o solo da erosão, e a prática da irrigação em terras inapropriadas, provocando, dentre outros problemas, a salinização dos solos.

Devido à falta de estratégias alternativas de sobrevivência, os agricultores utilizam os recursos naturais de maneira intensiva, como a vegetação que serve de alimento, a água para beber e para a higiene, a lenha utilizada como fonte de energia, que, normalmente, são super explorados e não podem se regenerar naturalmente, pelo menos num curto espaço de tempo. Os nutrientes e a matéria orgânica do solo diminuem devido à agricultura praticada, que extrai elementos nutritivos em quantidades superiores à capacidade de regeneração natural do solo, evitando sua reconstituição. $\mathrm{O}$ resultado é um efeito acumulativo da degradação do ambiente e da pobreza, causas principais da desertificação. (Drumond et al., 2004).

Segundo Brasil (2004), para lutar contra a desertificação, uma ação coerente e coordenada deve articular os meios e os conhecimentos práticos de todos. Este esforço inclui compromissos nos níveis federal, estadual e municipal, específicos para uma ação concreta em escala local que combata a desertificação com o maior sinergismo.

Ainda, segundo o Brasil (2004), a luta contra a desertificação compreende todas as atividades que melhorem as terras das zonas áridas, semiáridas e subúmidas secas, com a perspectiva do desenvolvimento sustentável. Os objetivos dessa luta, dentre outros, são prevenir ou atenuar a degradação das terras; recuperar as terras e os solos já degradados; informar constantemente e sensibilizar, a população diretamente afetada, sobre os problemas da desertificação em todos os níveis; melhorar o contexto social; combater a pobreza; melhorar a educação e as condições de saúde; e desenvolver a educação sobre a gestão sustentável dos recursos naturais.

Os processos de desertificação na Região de Desenvolvimento Sertão do São Francisco (RDSF) não só se manifestam pela sensibilidade 
natural do ambiente, mas, sobretudo, pelo uso a ele imposto. As práticas agrícolas inapropriadas concorrem fortemente para o agravamento do problema.

A vegetação nativa desta região tem sido bastante modificada pelo homem. Os estudos mais recentes indicam que os solos vêm sofrendo um processo intenso de desertificação devido à substituição da vegetação natural por campos de cultivos, pastagens e outros usos alternativos da terra.

A cobertura vegetal é, talvez, o mais importante dos fatores de controle do fenômeno da desertificação no espaço semiárido. Mesmo decídua, a caatinga não deixa de desempenhar o papel de protetor do solo contra as intempéries, diminuindo a sua degradação. Esta constatação afirma, categoricamente, que a principal causa da erosão nessa região é, sem dúvida, a devastação desenfreada da vegetação com os objetivos do atendimento da necessidade de mais áreas agrícolas e do fornecimento de madeira para cercas e outros fins. Quando o desmatamento se faz a corte raso, com vista ao aproveitamento agropecuário, a terra tende a permanecer desprotegida por longos períodos de tempo, em decorrência da itinerância das explorações e, principalmente, da baixa capacidade de regeneração da vegetação nativa em determinados locais. Entretanto, Mendes (1994) enfatiza que tanto o desmatamento com finalidade agrícola, localizado e perfeitamente individualizado, contribui para a degradação do meio, como também, aquele determinado pelo extrativismo seletivo e irracional, que leva à perda da biodiversidade. Este tipo de exploração, por não ocorrer em áreas contíguas e sim de modo seletivo, explorando os indivíduos mais nobres, vem, imperceptivelmente, comprometendo gradativa e continuadamente o efeito protetor da cobertura vegetal.

Ainda, segundo esse mesmo autor, o desmatamento é a principal causa tanto da desertificação como da diminuição da biodiversidade. A retirada da cobertura vegetal elimina quase que totalmente a diversidade vegetal e reduz a animal pela alteração do habitat, além de desproteger o solo dos agentes erosivos (ventos e chuvas) e aumenta o albedo da área e a temperatura do solo, o que propicia a oxidação da sua matéria orgânica. O solo nu e desprotegido fica exposto às erosões eólica e hídrica e arrastam as pequenas partículas (argila, silte e grânulos orgânicos), tornando-o menos fértil e com menor capacidade de armazenamento de água. Qualquer que seja a situação, não se pode tratar os problemas do desgaste do solo independentemente da sua vinculação com a cobertura vegetal.

Diante do exposto, este artigo tem como objetivo o mapeamento da desertificação da Região de Desenvolvimento Sertão do São Francisco, tendo como base o cruzamento das informações sobre a cobertura vegetal natural e das classes de solos.

\section{Material e Métodos}

Localizada na Região do Semiárido Pernambucano, a Região de Desenvolvimento Sertão do São Francisco (RDSF) tem uma área de $14.778 \mathrm{~km}^{2}$ e é formada por sete municípios: Afrânio, Cabrobó, Dormentes, Lagoa Grande, Orocó, Petrolina e Santa Maria da Boa Vista (Figura 1). De acordo com o censo demográfico de 2010, do IBGE, vive uma população de 434.713 habitantes, sendo 280.787 habitantes na área urbana e 153.926 habitantes na zona rural.

O município de maior população é Petrolina, com 294.081 habitantes, seguido por Santa Maria da Boa Vista, com 39.473 habitantes. A economia do Sertão do São Francisco é baseada na agricultura irrigada às margens do Rio São Francisco (com destaque para a fruticultura e horticultura) e na agroindústria, sobretudo com a produção de vinhos finos de mesa conhecidos nacional e internacionalmente.

O Vale do São Francisco é o maior polo exportador de frutas do Brasil, com destaque para a uva e a manga, responsáveis por $93 \%$ e $90 \%$, respectivamente, das vendas externas. É, também, o maior produtor de uvas de mesa do país.

A região caracteriza-se por apresentar um período seco que varia, normalmente, de 6 a 8 meses, com precipitações pluviométricas muito irregulares tendo médias anuais na faixa de 400 a $800 \mathrm{~mm}$. As temperaturas apresentam média anual na faixa de $24{ }^{\circ} \mathrm{C}$ a $26{ }^{\circ} \mathrm{C}$, podendo ser mais baixas em ambientes mais elevados, com uma média ao redor de $22{ }^{\circ} \mathrm{C}$ (Silva et al., 1993; Jacomine, 1996).

Na região semiárida, os solos resultam da ação combinada dos seus fatores de formação, isto é, do material de origem (geologia), principalmente, do clima, do relevo, da ação dos organismos e do tempo, bem como dos seus processos de formação. Tais processos levam a diferenciação de horizontes pedogenéticos que se destacam entre si e em relação ao material de origem (rochas ou sedimentos), de acordo com Santos et al. (2006). Em regiões secas como a região semiárida a geologia (litologia) passa a assumir, cada vez mais, destaque no conjunto de 
características e propriedades dos solos. Desta forma, as principais características relativas aos solos no ambiente semiárido, sobretudo os desenvolvidos de rochas cristalinas, refletem forte correlação com o material de origem e a influência do relevo.

Existem muitas variações ambientais ao se percorrer o semiárido, desde as chapadas mais altas até as zonas mais baixas, como a depressão sertaneja. Os solos predominantes nas diferentes paisagens da região de estudo são os Latossolos, Argissolos, Planossolos, Luvissolos e Neossolos (Brasil, 1972). Em baixas proporções têm-se os Nitossolos, Chernossolos, Cambissolos, Vertissolos e Plintossolos (Brasil, 1972; Oliveira et al., 1992; Jacomine, 1996; Araújo Filho et al., 2001).

A desertificação é um fenômeno de extraordinária complexidade ambiental e social. O número de indicadores e variáveis em que intervém dificulta uma visão de conjunto que integre em sua devida medida a todos os elementos componentes. Tendo em vista a impossibilidade de análise exaustiva de todas as variáveis consideradas, é necessário selecionar um conjunto de variáveis que, por sua importância ou por serem indicadores que integrem a uma cadeia de processos, agreguem o máximo de informação no momento de compreender tanto o estado como as tendências do processo de desertificação. Assim, utilizamos no presente trabalho a metodologia descrita por Sá et al. (2014), cujo estudo lança mão de duas variáveis que possam explicar a natureza do fenômeno. A primeira foi o recorte do mapeamento da cobertura vegetal da RDSF, realizado com o uso de imagens do sensor ETM+ da série Landsat 5 e 7. Tal mapeamento foi procedido utilizando-se o Manual Técnico da Vegetação Brasileira (IBGE, 2012), como referência para o estabelecimento da legenda final. As informações da cobertura vegetal e do uso das terras foram obtidas a partir dos dados do Projeto de Conservação e Utilização Sustentável da Biodiversidade Brasileira (PROBIO), Levantamento da Cobertura Vegetal e Uso do Solo do Bioma Caatinga), na escala 1:100.000 (MMA, 2007). De acordo com este manual, os tipos de vegetação ou classes de vegetação predominantes na RDSF são a Savana Estépica Arborizada (Ta), seguida pelas áreas ocupadas pela agropecuária (Ag) e Savana Estépica Florestada (Td). Além das formações citadas, a região apresenta também a classe de Formações com influência fluvial

$(\mathrm{Pa})$.

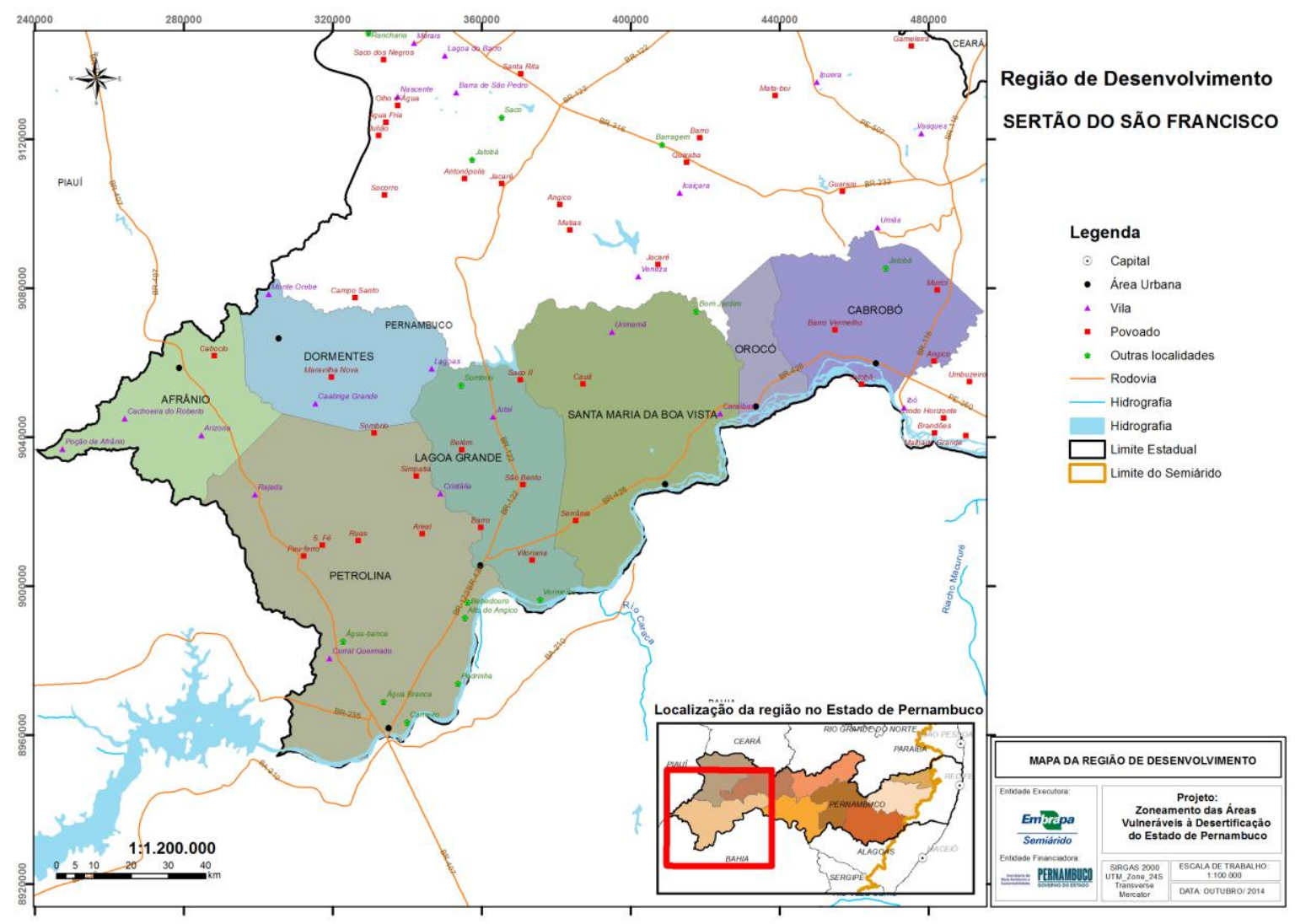

Figura 1. Localização da área de estudo. 
As Savanas-estépicas florestadas (Td) são os subgrupos de formações caracterizadas por micro e/ou nanofanerófitos, com média de $5 \mathrm{~m}$, excepcionalmente ultrapassando os $7 \mathrm{~m}$ de altura, mais ou menos densos, com grossos troncos e esgalhamento bastante ramificado em geral provido de espinhos e/ou acúleos, com total deciduidade na época de estiagem.

As Savanas-estépicas arborizadas (Ta) são os subgrupos de formações que apresentam as mesmas características florísticas da fisionomia ecológica anterior, porém os indivíduos que o compõem são mais baixos, existindo claros entre eles.

As Formações com influência fluvial (Pa) são as comunidades vegetais das planícies aluviais que refletem os efeitos das cheias dos rios nas épocas chuvosas, ou, então, das depressões alagáveis todos os anos. Nestes terrenos aluviais, conforme a quantidade de água empoçada e ainda o tempo que ela permanece na área, as comunidades vegetais vão desde a pantanosa até os terraços alagáveis temporariamente.

As áreas ocupadas pela agropecuária $(\mathrm{Ag})$ são aquelas onde a cobertura vegetal original foi substituída para dar lugar às atividades agrícolas e de pecuárias.

A segunda variável foi o recorte do mapeamento das classes de solos presentes na RDSF, tomando-se como base de referência o Sistema Brasileiro de Classificação de Solos da Embrapa (EMBRAPA, 2006).

As informações de solos foram obtidas por intermédio da Embrapa Solos, em trabalho publicado em 2001 no trabalho intitulado ZAPE (Zoneamento Agroecológico de Pernambuco). Esta publicação apresenta o levantamento de solos de todo o Estado na escala de 1:100.000 (EMBRAPA SOLOS, 2001).

Os solos predominantes na RDSF são os Latossolos, Cambissolos, Argissolos Vermelho amarelos, Neossolos Flúvicos, Neossolos Litólicos e Luvissolos descritos em (Santos et al., 2006; Ribeiro et al., 2009).

Os Latossolos constituem solos profundos, bem drenados, porosos a muito porosos, friáveis, com horizonte superficial pouco espesso e com baixos teores de matéria orgânica. Os Latossolos Amarelos e Vermelho-Amarelos apresentam textura predominantemente média a argilosa e uniforme ao longo do perfil e possuem baixa capacidade de troca de cátions - CTC. São, predominantemente, ácidos e quimicamente pobres, ocupando grandes extensões nas chapadas e nas áreas de coberturas. Em virtude da grande profundidade efetiva, com boa retenção e disponibilidade de água e relevo plano ou suave em que ocorrem, podem ser considerados de baixo risco de desertificação.

Os Cambissolos são solos que variam de fortemente até imperfeitamente drenados, rasos a profundos, de cor bruna ou bruno-amarelada, de alta a baixa saturação por bases e atividade química da fração coloidal. $\mathrm{O}$ horizonte $\mathrm{B}$ incipiente $(\mathrm{Bi})$ tem textura franco-arenosa ou mais argilosa e o solum, geralmente, apresenta teores uniformes de argila, podendo ocorrer ligeiro decréscimo ou um pequeno incremento de argila do horizonte A para o Bi. A estrutura do horizonte Bi pode ser em blocos, granular ou prismática, havendo casos, também, de solos com ausência de agregados, com grãos simples ou maciços.

Os Argissolos Vermelho Amarelos são solos medianamente profundos a profundos, moderadamente a bem drenados, tendo horizonte B textural com textura média a argilosa, de cores vermelhas a amarelas, abaixo de um horizonte A ou E, de cores mais claras e textura arenosa ou média, com baixos teores de matéria orgânica. Apresentam argila de atividade baixa e saturação por bases variável. Desenvolvem-se a partir de diversos materiais de origem, em áreas de relevo plano a montanhoso. A maioria dos solos desta classe apresenta um evidente incremento no teor de argila, com ou sem decréscimo, do horizonte B para baixo no perfil. A transição entre os horizontes A e Bt é, usualmente, clara, abrupta ou gradual.

Os Neossolos Flúvicos são solos derivados de sedimentos aluviais com horizonte A assente sobre um horizonte $\mathrm{C}$ constituído de camadas estratificadas, sem relação pedogenética entre si. São pouco evoluídos, desenvolvidos de camadas de sedimentos aluviais recentes. Em geral as camadas apresentam espessura e granulometria bastante diversificadas, tanto no sentido vertical quanto no horizontal dos perfis de solo, devido à heterogeneidade de deposição do material originário. Todavia, existe situação pouco nítida, sobretudo quando as camadas são muito espessas. Compreendem os solos anteriormente classificados como Solos Aluviais.

Os Neossolos Litólicos ocorrem em toda a região semiárida, principalmente nas áreas mais acidentadas, onde são encontrados afloramentos rochosos. São muito pouco desenvolvidos, rasos, não hidromórficos, apresentando horizonte $\mathrm{A}$ diretamente sobre a rocha ou horizonte $\mathrm{C}$ de 
pequena espessura. São, normalmente, pedregosos e/ou rochosos, moderadamente a excessivamente drenados, com horizonte A pouco espesso, cascalhento, de textura predominantemente média, podendo, também, ocorrer solos de textura arenosa, siltosa ou argilosa. Podem ser distróficos ou eutróficos, ocorrendo, geralmente, em áreas de relevo suave ondulado a montanhoso. Correspondem à classe de solos anteriormente denominada de Solos Litólicos.

Por fim, os Luvissolos que são solos rasos a pouco profundos, com horizonte $\mathrm{B}$ textural de cores vivas e argila de atividade alta, apresentando horizonte A fraco, de cor clara, pouco espesso, maciço ou com estrutura fracamente desenvolvida. São moderadamente ácidos a neutros, com elevada saturação por bases. Apresentam, frequentemente, revestimento pedregoso na superfície (pavimento desértico) ou na massa do solo e, normalmente, possuem uma crosta superficial de 5 a $10 \mathrm{~mm}$ de espessura, além de altos teores de silte. São altamente susceptíveis aos processos erosivos, em virtude da grande diferença textural entre $\mathrm{o}$ horizonte $\mathrm{A}$ e $\mathrm{o}$ horizonte $\mathrm{Bt}$.

Foram estabelecidos os seguintes critérios com relação à cobertura vegetal numa escala de severidade da desertificação que vai desde as áreas com ausência do problema, onde temos uma vegetação bastante protetora dos solos, passando pelos níveis fraco, moderado acentuado e severo, onde a cobertura é muito escassa ou mesmo ausente, totalizando quatro níveis de severidade. Quanto às classes de solos, foram utilizados os critérios de susceptibilidade à erosão descritos por Lima et al. (2002), totalizando cinco situações de susceptibilidade à degradação. Quanto menor o nível atribuído, menor será a erodibilidade daquela classe de solo, como observado na Tabela 1. Ainda, segundo esse mesmo autor, a erodibilidade, maior ou menor de um solo, dependerá de suas propriedades, que são bem estudadas e avaliadas por processos diretos e indiretos. A natureza do solo é um dos fatores que exerce maior influência sobre a quantidade e qualidade do material erodido. Essa influência depende das características físicas (permeabilidade), morfológicas (textura, estrutura e profundidade) e químico-mineralógicas (natureza dos componentes da fração argila). É muito comum no Semiárido solos rasos ou pouco profundos, pedregosos, e possuidores muitas vezes de horizonte A de textura arenosa, o que favorece os processos de erosão e degradação dos mesmos, como no caso de alguns Argissolos, Neossolos Litólicos, Luvissolos e Planossolos (Araújo Filho et al., 2001).

Tabela 1. Escala de susceptibilidade à desertificação para a cobertura vegetal e classes de solos. Cobertura vegetal Classes de solos

\begin{tabular}{cccc} 
Classes & Nível & Classes & Nível \\
\hline $\mathrm{Td}$ & Fraco & Latossolos & Fraco \\
$\mathrm{Ta}$ & Moderado & Cambissolos & Moderado \\
$\mathrm{Pa}$ & Acentuado & Argissolo Vermelho Amarelo & Acentuado \\
$\mathrm{Ag}$ & Severo & Neossolo Flúvico & Acentuado \\
& & Neossolo Litólico & Acentuado \\
& & Luvissolo & Severo \\
\hline
\end{tabular}

\section{Resultados e Discussão}

Dada à característica multidisciplinar da desertificação, os trabalhos sobre o tema, normalmente, utilizam um conjunto de indicadores da mais variada natureza. As diferenças no número e tipo de indicadores e nos critérios de classificação das áreas potencialmente suscetíveis à desertificação têm levado à produção de mapas que, como era de se esperar, diferem na área e/ou no grau de ocorrência da desertificação.
No caso específico da RDSF, utilizamos as duas variáveis que melhor expressam o desencadeamento dos processos de desertificação, a cobertura vegetal e as classes de solos.

A partir do mapeamento da cobertura vegetal (Figura 2) e dos índices de sensibilidade à desertificação adotada para estas classes de cobertura (Tabela 1), foi gerado o mapa de sensibilidade à desertificação para esta variável (Figura 3). 
Para a variável classe de solos, tomando-se como base o mapa de classes de solos (Figura 4) e os critérios de sensibilidade à desertificação (Tabela1), foi gerado o mapa de sensibilidade á desertificação para a classe de solos (Figura 5).

Com base nestes dois mapeamentos, realizou-se a integração espacial com a operação de intersecção. As feições de ambas as informações se sobrepuseram, ocorrendo o cruzamento dos polígonos, gerando novas feições e os atributos das informações foram mantidos. Por fim, realizou-se a análise das duas variáveis utilizadas em relação à desertificação (Tabela 2), e o resultado desta operação resultou no mapa final de susceptibilidade (Figura 6). Na Tabela 3 é apresentado o quantitativo de áreas conforme o nível de susceptibilidade à desertificação por município.

O estado de Pernambuco, segundo o PAE/PE (2009), possui uma área territorial de 98.311,6 km². Considerando os critérios adotados pelo Brasil (2004), cerca de $90.000 \mathrm{~km}^{2}$ correspondem às áreas susceptíveis à desertificação, equivalentes a 90,68\% do território estadual. Destes, 16,57\% correspondem à RDSF, com alta susceptibilidade à desertificação. O restante corresponde às áreas subúmidas secas $\mathrm{e}$ as áreas do entorno.

As áreas susceptíveis à desertificação na RDSF têm crescimento associado às ações humanas como desmatamento acelerado, uso desordenado e inadequado do solo. Municípios como Dormentes, Cabrobó e Afrânio estão submetidos a níveis muito graves de desertificação.

$\mathrm{Na}$ RDSF prevalecem as associações de Luvissolos, Neossolos Litólicos, Argissolos e Tabela 2. Classificação da sensibilidade à desertificação com base no cruzamento das bases da cobertura vegetal e das classes de solos da Região de Desenvolvimento Sertão do São Francisco.

\begin{tabular}{llllll}
\hline vegetal & Cobertura & Td & Ta & Pa & Ag
\end{tabular}

\section{Classes de Solos}

\begin{tabular}{l}
\hline Latossolos \\
Cambissolos \\
Argissolo Vermelho amarelo \\
Neossolo Flúvico \\
Neossolos litólicos \\
Luvissolos \\
\hline
\end{tabular}

Legenda: Azul: Ausente; Verde: Fraco; Amarelo: Moderado; Laranja: Acentuado e Vermelho: Severo
Planossolos revestidos por Savanas Estépicas de variados padrões fisionômicos e florísticos. A pecuária extensiva e agricultura tecnificada e também de subsistência são as atividades predominantes nestes sertões semiáridos.

Os processos de desertificação da RDSF estão associados ao regime pluviométrico irregular e com secas recorrentes; às taxas elevadas de evaporação e de evapotranspiração com balanço hídrico deficitário; ao médio potencial de recursos hídricos superficiais, exceção ao Rio São Francisco e médio a baixo de águas subterrâneas; solos rasos a medianamente profundos com eventuais ocorrências de chãos pedregosos; vulnerabilidade moderadamente alta à expansão da desertificação em função de processos erosivos muito ativos.

Procurou-se com este trabalho fornecer um agregado de informações espacializadas a respeito das áreas susceptíveis à desertificação na RDSF, que possa ser útil na identificação das áreas críticas que necessitam prioritariamente de mais atenção.

Essas informações deverão nortear o aprofundamento das pesquisas e das ações de prevenção e de combate à desertificação e de mitigação dos efeitos das secas. Os resultados derivados do estudo subsidiarão a construção de um banco de dados sobre a vulnerabilidade ambiental da RDSF.

Em termos científicos espera-se que, a partir deste índice de desertificação gerado, seja possível espacializar os níveis de desertificação de todo o semiárido pernambucano e que possa ser replicado em todo semiárido brasileiro. 
Revista Brasileira de Geografia Física vol. 08, número especial (IV SMUD) (2015) 510-524.

Tabela 3. Quantificação das áreas susceptíveis à desertificação com base no cruzamento da Cobertura vegetal e classes de solos da Região de Desenvolvimento Sertão do São Francisco.

\begin{tabular}{|c|c|c|c|c|c|c|c|c|c|}
\hline \multirow[b]{2}{*}{ Município } & \multicolumn{2}{|c|}{ Ausente/Fraco } & \multicolumn{2}{|c|}{ Moderado } & \multicolumn{2}{|c|}{ Acentuado } & \multicolumn{2}{|c|}{ Severo } & \multirow{2}{*}{$\begin{array}{c}\text { Área } \\
\text { Município } \\
\left(\mathbf{k m}^{2}\right)\end{array}$} \\
\hline & $\begin{array}{l}\text { Área } \\
\left(\mathbf{k m}^{2}\right)\end{array}$ & $\%$ & $\begin{array}{l}\text { Área } \\
\left(\mathbf{k m}^{2}\right)\end{array}$ & $\%$ & $\begin{array}{l}\text { Área } \\
\left(\mathbf{k m}^{2}\right)\end{array}$ & $\%$ & $\begin{array}{l}\text { Área } \\
\left(\mathbf{k m}^{2}\right)\end{array}$ & $\%$ & \\
\hline Afrânio & 1,89 & 0,13 & 1015,96 & 67,84 & - & 0,00 & 479,73 & 32,03 & 1497,59 \\
\hline Cabrobó & 33,68 & 2,03 & 1224,41 & 73,92 & - & 0,00 & 398,36 & 24,05 & 1656,45 \\
\hline Dormentes & 0,76 & 0,05 & 706,16 & 45,93 & - & 0,00 & 830,69 & 54,02 & 1537,61 \\
\hline Lagoa Grande & 20,78 & 1,12 & 1465,76 & 79,31 & - & 0,00 & 361,72 & 19,57 & 1848,25 \\
\hline Orocó & 48,68 & 8,01 & 461,69 & 76,01 & - & 0,00 & 97,07 & 15,98 & 607,44 \\
\hline Petrolina & 64,55 & 1,41 & 3606,24 & 78,75 & 51,08 & 1,12 & 857,73 & 18,73 & 4579,60 \\
\hline $\begin{array}{l}\text { Santa Maria da Boa } \\
\text { Vista }\end{array}$ & 91,84 & 3,01 & 2564,56 & 84,05 & - & 0,00 & 394,69 & 12,94 & 3051,09 \\
\hline Total Geral & 262,19 & 1,77 & 11044,77 & 74,74 & 51,08 & $\mathbf{0 , 3 5}$ & 3419,99 & 23,14 & 14778,03 \\
\hline
\end{tabular}




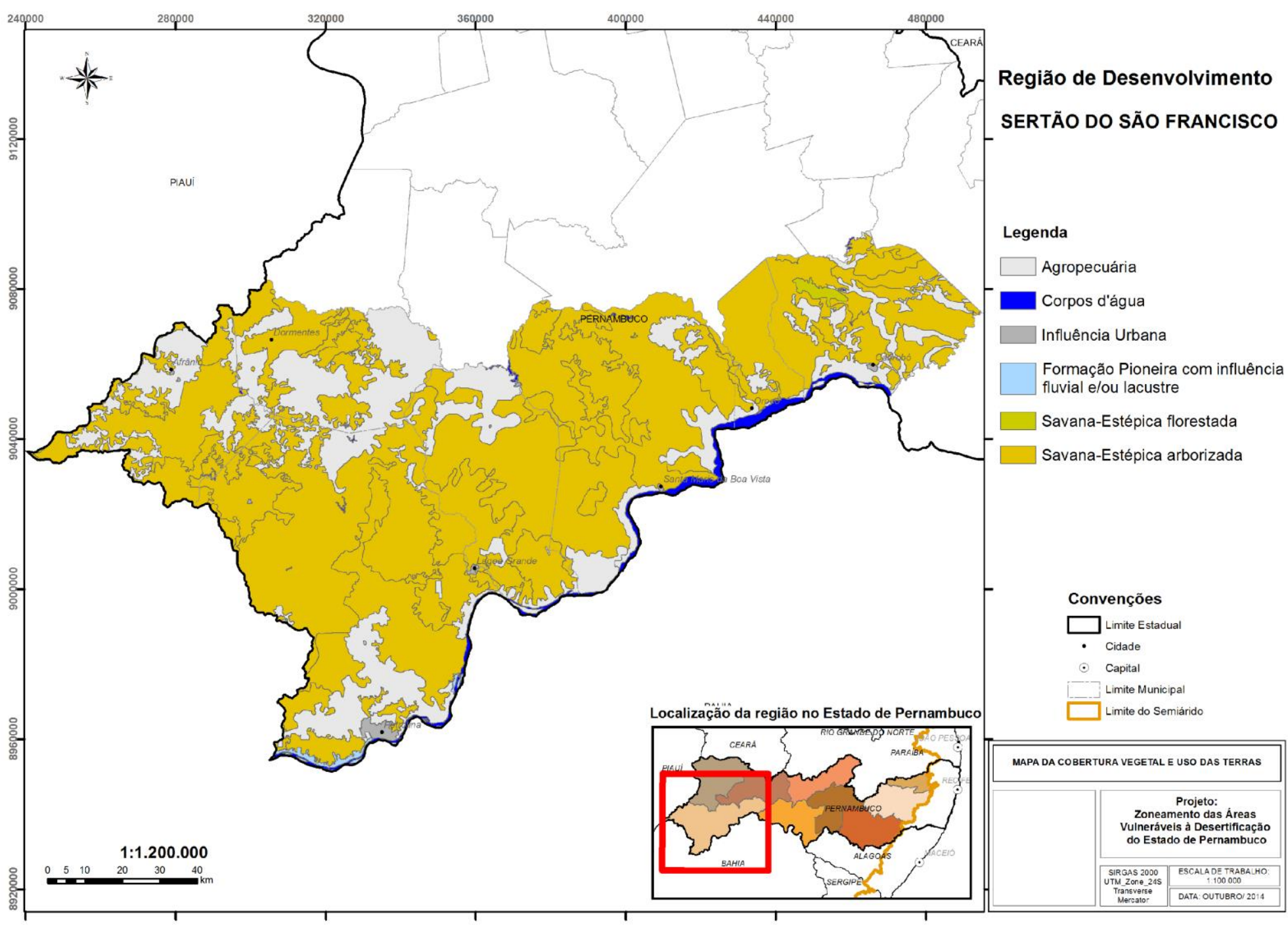

Figura 2. Mapa da cobertura vegetal da Região de Desenvolvimento Sertão do São Francisco. 
Revista Brasileira de Geografia Física vol. 08, número especial (IV SMUD) (2015) 510-524.

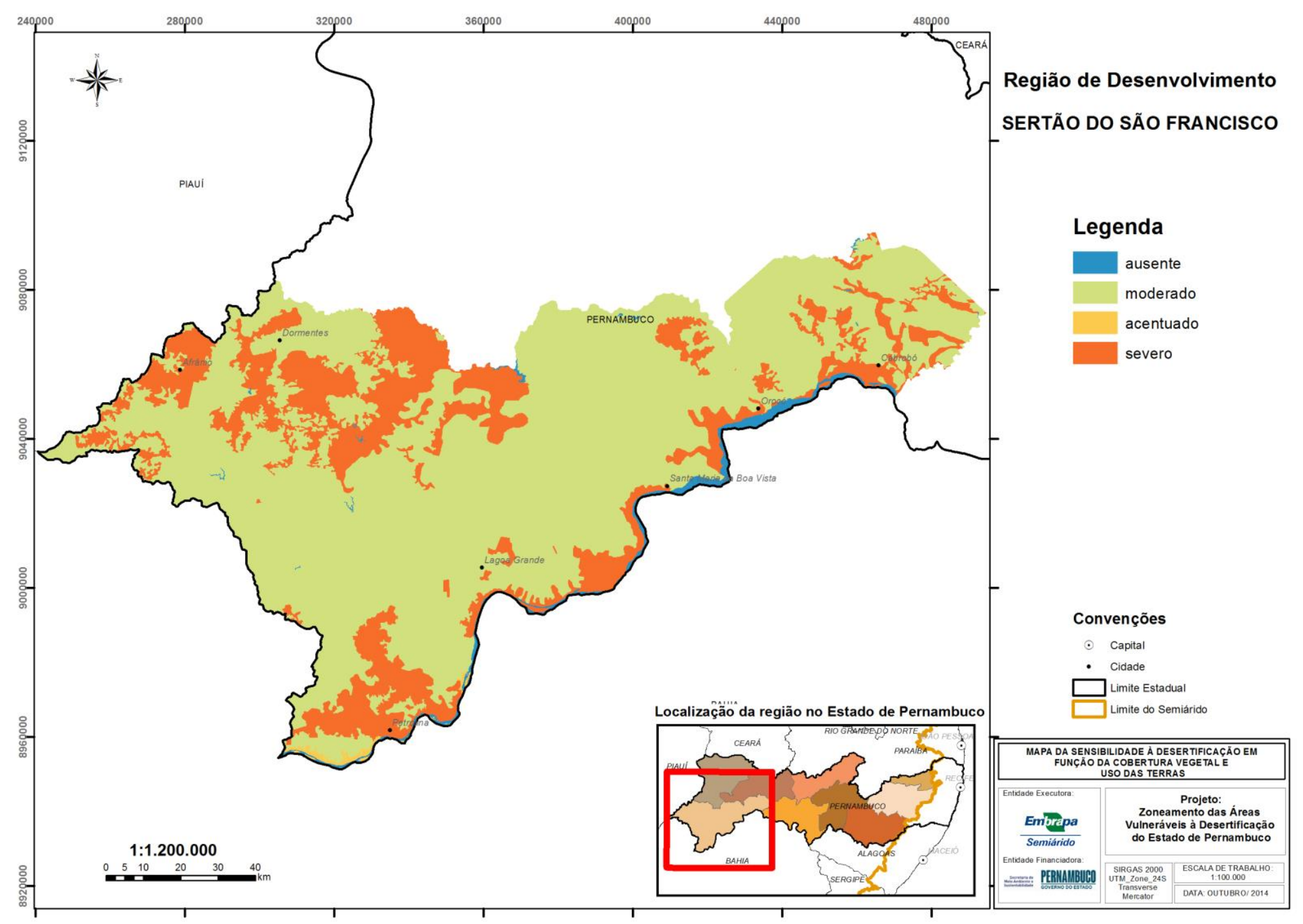

Figura 3. Mapa de sensibilidade à desertificação para a cobertura vegetal da Região de Desenvolvimento Sertão do São Francisco. 
Revista Brasileira de Geografia Física vol. 08, número especial (IV SMUD) (2015) 510-524.

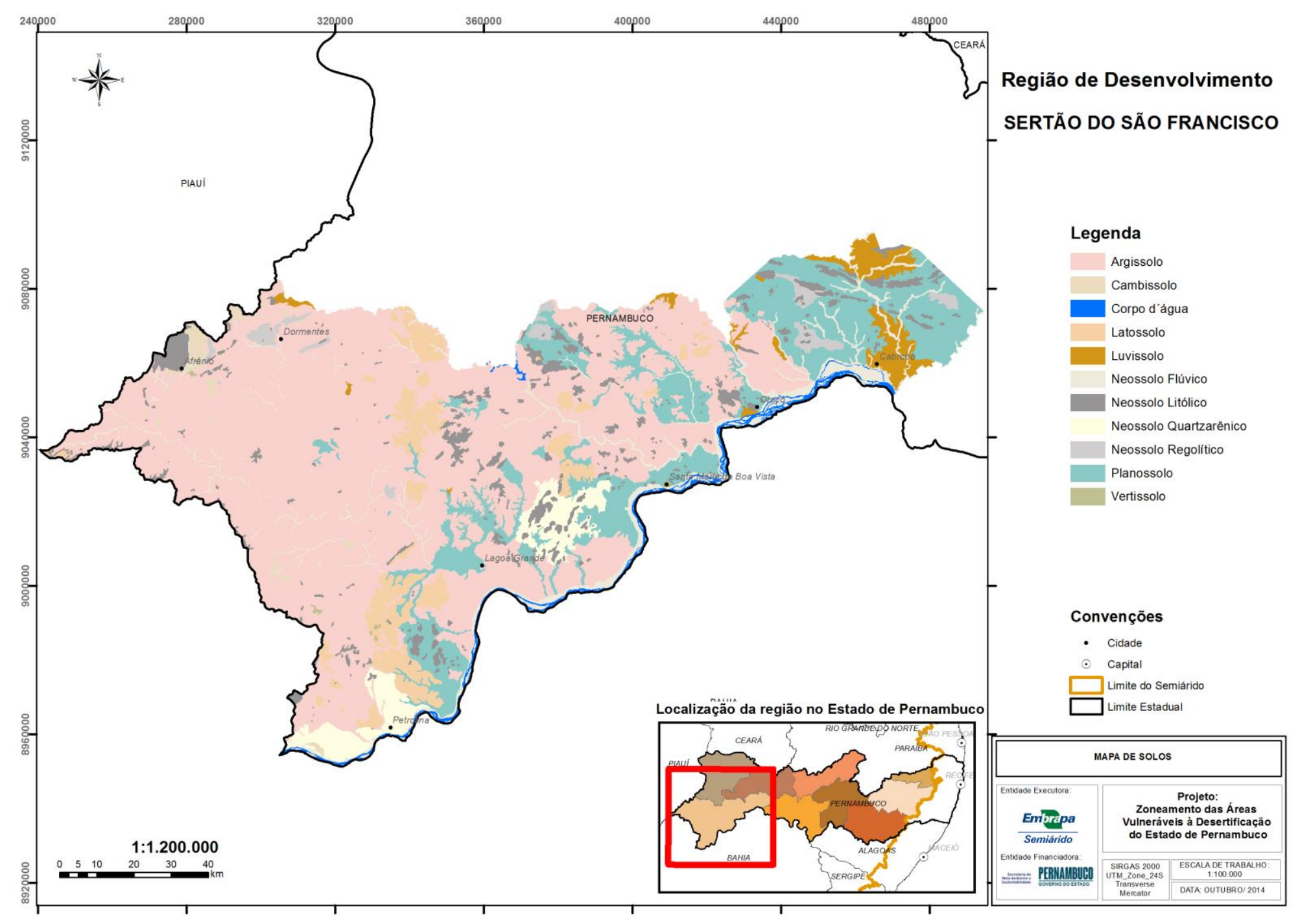

Figura 4. Mapa dos solos da Região de Desenvolvimento Sertão do São Francisco. 
Revista Brasileira de Geografia Física vol. 08, número especial (IV SMUD) (2015) 510-524.

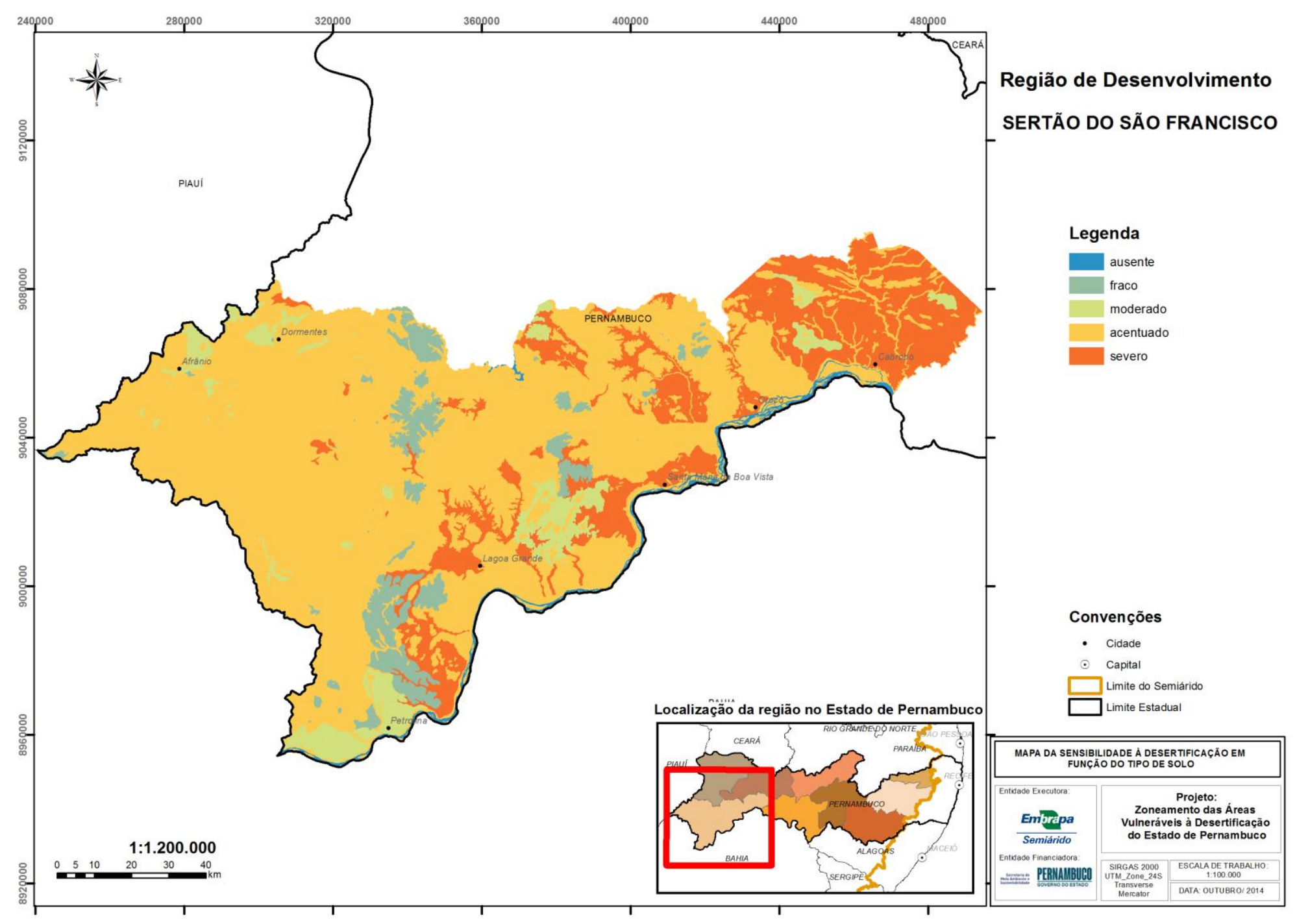

Figura 5. Mapa de sensibilidade à desertificação para a classe de solos da Região de Desenvolvimento Sertão do São Francisco. 
Revista Brasileira de Geografia Física vol. 08, número especial (IV SMUD) (2015) 510-524.

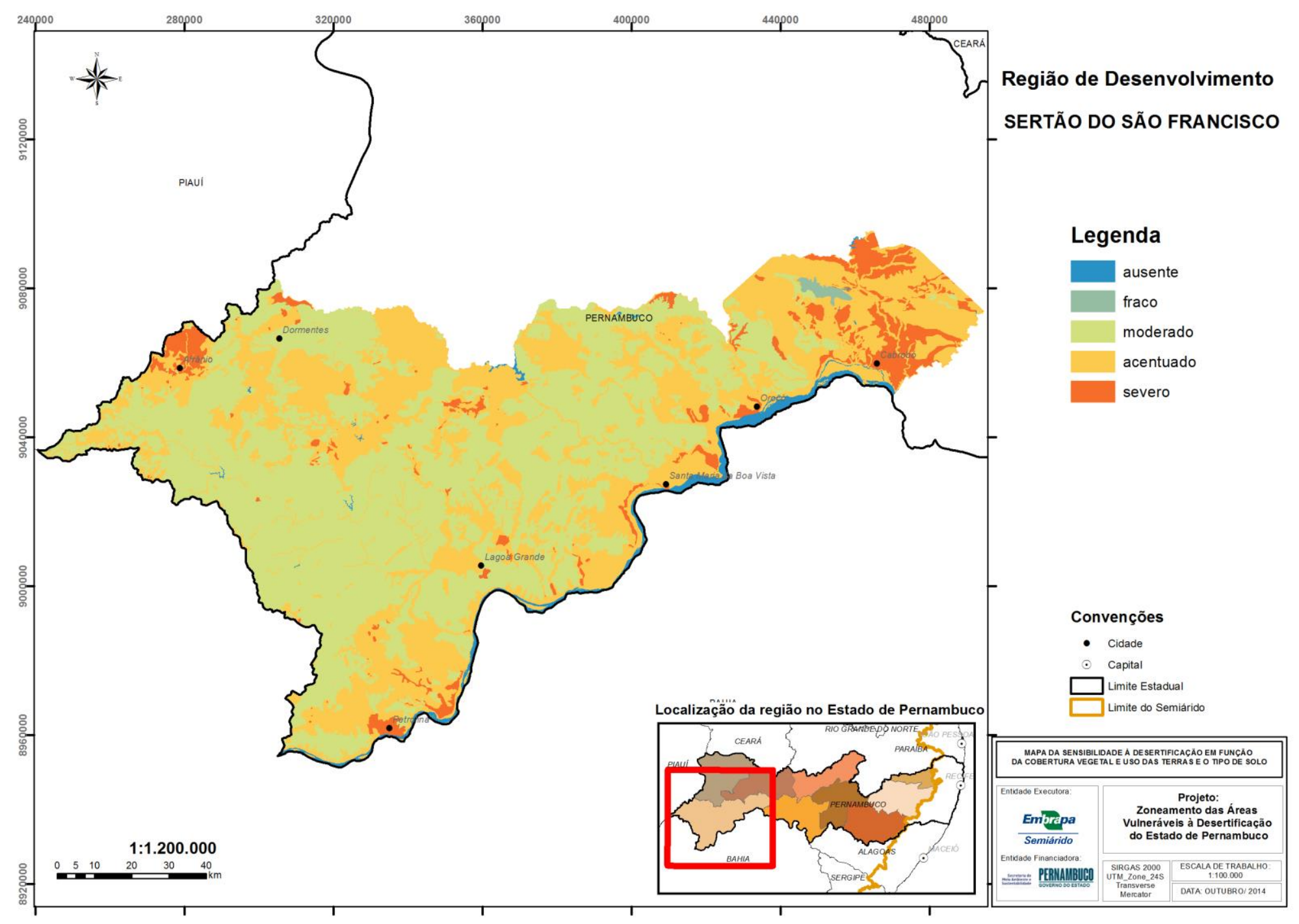

Figura 6. Mapa da sensibilidade à desertificação com base na cobertura vegetal e nas classes de solos da Região de Desenvolvimento Sertão do São Francisco. 


\section{Conclusões}

1. A Região de Desenvolvimento Sertão do São Francisco (RDSF) apresenta grande diversidade tanto da Cobertura vegetal quanto das classes de solos;

2. Do ponto de vista da Cobertura vegetal, observa-se que a Classe de Sensibilidade à desertificação moderada tem maior expressão em área que as demais coberturas;

3. No que diz respeito aos solos, observa-se que a maioria das classes presentes está relacionada como sendo de sensibilidade à desertificação nos níveis entre acentuado e severo;

4. Da análise conjunta das duas variáveis, verifica-se que aproximadamente $24 \%$ da Região de Desenvolvimento Sertão do São Francisco encontram-se na situação de sensibilidade à desertificação em que predominam as classes Acentuada e Severa e $75 \%$ na condição de desertificação Moderada.

\section{Referências}

Araújo Filho, J.C., Silva, A.B., Silva, F.B.R. e, Leite, A.P., 2001. Diagnóstico ambiental do município de Floresta, Pernambuco. Embrapa Solos, Rio de Janeiro. (Embrapa Solos. Circular técnica, 10).

BRASIL, 1972. Ministério da Agricultura. Departamento Nacional de Pesquisa Agropecuária. Divisão de Pesquisa Pedológica. Levantamento exploratório-reconhecimento de solos do Estado de Pernambuco. DNPEA; SUDENE.DRN, Recife. (DNPEA. Boletim técnico, 26; SUDENE. DRN. Série Pedologia, 14).

BRASIL, 2004. Ministério do Meio Ambiente. Secretaria de Recursos Hídricos. Programa de Ação Nacional de Combate à Desertificação e Mitigação dos Efeitos da Seca - PAN-BRASIL. Brasília.

Drumond, M.A., Kiill, L.H.P., Lima, P.C.F., Oliveira, M.C., Oliveira, V.R.de, Albuquerque, S.G.de, Nascimento, C.E.deS., Cavalcanti, J., 2004. Estratégias para o uso sustentável da biodiversidade da caatinga, in: Silva, J.M.C.da, Tabarelli, M., Fonseca, M.T.da, Lins, L.V. (Orgs.), Biodiversidade da Caatinga: áreas e ações prioritárias para a conservação. Ministério do
Meio Ambiente; Universidade Federal de Pernambuco, Brasília, pp. 329-340.

EMBRAPA. Empresa Brasileira de Pesquisa Agropecuária, 2006. Sistema Brasileiro de Classificação de Solos. Santos et al. (Eds), 2. ed. Embrapa Solos, Rio de Janeiro.

EMBRAPA SOLOS. Unidade de Execução de Pesquisa e Desenvolvimento do Recife, 2001. Zoneamento Agroecológico: Pernambuco crescendo por inteiro. Embrapa Solos-UEP; Governo do Estado de Pernambuco, Secretaria de Produção Rural e Reforma Agrária, Recife. 1 CDROM.

IBGE. Instituto Brasileiro de Geografia e Estatística, 2012. Manual Técnica da Vegetação Brasileira. IBGE, Rio de Janeiro. (IBGE. Séries Manuais Técnicos em Geociências, 1).

Jacomine, P.K.T., 1996. Solos sob caatinga: características e uso agrícola, in: Alvarez, V.V.H., Fontes, L.E.F., Fontes, M.P.F. O Solo nos Grandes Domínios Morfoclimáticos do Brasil e o Desenvolvimento Sustentável. UFV; SBCS, Viçosa, pp. 95-133.

Lima, A.A.C., Oliveira, F.N.S., Aquino, A.R.L.de, 2002. Limitações do uso dos solos do Estado do Ceará por suscetibilidade à erosão. Embrapa Agroindústria Tropical, Fortaleza. (Embrapa Agroindústria Tropical. Documentos, 54).

Mendes, B.V., 1994. Uso e conservação da biodiversidade no semiárido. GT1 Recursos Naturais e Meio Ambiente. Projeto Áridas, Uma Estratégia de Desenvolvimento Sustentável para o Nordeste, Fortaleza. Presidência da Republica.

MMA. Ministério do Meio Ambiente, 2007. Levantamento da cobertura vegetal e do uso do solo do Bioma Caatinga. Brasília.

Oliveira, J.B., Jacomine, P.K.T., Camargo, M.N., 1992. Classes gerais de solos do Brasil: guia auxiliar para o seu reconhecimento. Funep, Jaboticabal.

PAE/PE. Programa de ação estadual de Pernambuco para o combate à desertificação e mitigação dos efeitos da seca. Secretaria de Ciência, Tecnologia e Meio Ambiente de Pernambuco, Recife.

Ribeiro, M.R., Sampaio, E.V.S.B., Galindo, I.C.L., 2009. Os solos e o processo de desertificação no Semiárido brasileiro, in: Tópicos em ciência do solo. SBCS, Viçosa, pp. 319-412. 
Revista Brasileira de Geografia Física vol. 08, número especial (IV SMUD) (2015) 510-524.

Sá, I.B., Cunha, T.F.da, Taura, T.A., Drumond, M.A., 2014. Mapeamento da desertificação da Região Sul cearense. Revista Brasileira de Geografia Física 7, 572-583.

Santos, H.G.dos, Jacomine, P.K.T., Anjos, L.H.C.dos, Oliveira, V.A.de, Oliveira, J.B.de, Coelho, M.R., Lumbreras, J.F., Cunha, T.J.F., 2006. Sistema brasileiro de classificação de solos. 2. ed. Embrapa Solos, Rio de janeiro.
Silva, F.B.R., Riché, G.R., Tonneau, J.P., Sousa Neto, N.C., Brito, L.T.L., Coreia, R.C., Cavalcanti, A.C., Silva, F.H.B.B., Silva, A.B., Araújo Filho, J.C., 1993. Zoneamento agroecológico do Nordeste: diagnóstico do quadro natural e agrossocioeconômico. EMBRAPACPATSA, Petrolina; EMBRAPA-CNPS, Recife; UEP, Recife. (EMBRAPA-CPATSA. Documentos,80). 